\title{
Prevalence of Human Immunodeficiency Virus and associated factors among Visceral Leishmaniasis infected patients in Northwest Ethiopia: a facility based cross- sectional study
}

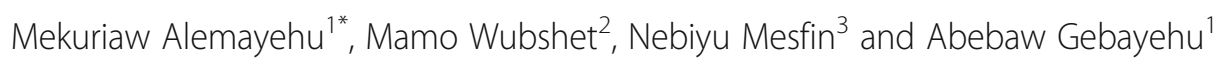

\begin{abstract}
Background: Visceral Leishmaniasis coinfection with HIV/AIDS has emerged as a series of disease pattern. It most often results in unfavorable responses to treatment, frequent relapses, and deaths. Scarce data is available regarding the prevalence of HIV and associated factors among Visceral Leishmaniasis coinfected patients. This study sought to determine the prevalence of HIV and associated factors among Visceral Leishmaniasis infected patients.

Methods: Facility based cross-sectional study was conducted from October, 2015 to August, 2016 in Northwest Ethiopia. Cluster sampling technique was used to select 462 Visceral Leishmaniasis infected patients. Serologic and parasitological test results have been used to diagnose Visceral Leishmaniasis. The HIV diagnosis was based on the national algorithm with two serial positive rapid test results. In case of discrepancy between the two tests, Uni-Gold ${ }^{T M}$ was used as a tie breaker. Structured questionnaire was used to collect independent variables. Data was entered by using Excel and analyzed by using SPSS version 20. Descriptive statistics and logistic regression model was used to analyze the data.
\end{abstract}

Results: A total of 462 study participants were included in the study with a response rate of $92.4 \%$. HIV and Visceral Leishmaniasis coinfection was found to be $17.75 \%$ with $95 \% \mathrm{Cl} ; 14.30-21.40$. Age $\geq 30$ years ( $\mathrm{AOR}=22.58,95 \% \mathrm{Cl} 11.34$, 45.01), urban residents $(A O R=2.02,95 \% \mathrm{Cl} 1.16,4.17)$ and daily laborer workers $(A O R=4.99,95 \% \mathrm{Cl} 2.33,10.68)$ were significantly associated with HIV and Visceral Leishmaniasis coinfection.

Conclusion: HIV and Visceral Leishmaniasis coinfection in the Northwest Ethiopia was found to be low. Age, residence and employment were independently associated with HIV-VL coinfection in the Northwest Ethiopia. It is better to design interventions to prevent and control HIV-VL coinfection for productive age groups (age $\geq 30$ ) and daily laborers.

Keywords: Visceral Leishmaniasis, Human immunodeficiency virus, Coinfection, Northwest Ethiopia

\footnotetext{
*Correspondence: mekuriaw14@gmail.com

'Institute of Public Health, College of Medicine and Health Sciences,

University of Gondar, Gondar, Ethiopia

Full list of author information is available at the end of the article
} 


\section{Background}

Visceral Leishmaniasis (VL; also known as "kala-azar") is a systemic parasitic disease caused by the parasite Leishmania donovani species complex. It is estimated about 500,000 new cases of VL occur annually worldwide [1]. VL is characterized by irregular bouts of fever, substantial weight loss, swelling of the spleen and liver, and anemia (which may be serious). If the disease is not treated, the fatality rate in developing countries can be as high as $100 \%$ within 2 years [2]. VL accelerates HIV replication and disease progression, mainly by chronic immune stimulation [3].

The prevalence of patients with both HIV and VL infection (hereafter, "HIV-VL coinfection") in Europe has fallen sharply since 1996, when antiretroviral treatment (ART) became standard [4, 5]. In India and particularly in Africa, HIV-VL coinfection is emerging [4, 5]. The AIDS pandemic has expanded to rural areas where VL is endemic, with cases of HIV-VL coinfection reported in 35 countries $[4,5]$, among which Ethiopia carries the greatest burden. The affected populations are mainly very poor male seasonal migrant workers that travel in the harvesting season from non endemic highlands to the cotton, sesame and sorghum fields of Humara and Metama, the VL endemic low lands situated on the Sudanese boarders $[6,7]$.

In Ethiopia, HIV prevalence has declined from $1.5 \%$ in 2011 to $1.1 \%$ in 2015 [8]. Hence, in spite of the decreasing prevalence of $\mathrm{HIV}$ in the general population, the prevalence of HIV among VL patients has remained proportionally very high. The prevalence of HIV-VL coinfection from different studies in Ethiopia range from 18.1 to $48.5 \%$ [9, 10]. The real burden is likely to be underestimated or overestimated because of rapid decrease of HIV infection in Ethiopia [8]. There is however knowledge gap on the current prevalence of HIV among VL infected patients.

In most of the studies done outside Ethiopia, factors associated with HIV-VL coinfection were advanced HIV-1 disease [11, 12], intravenous drug users $[11,13]$, CDC clinical category $C[14,15]$ and CD4 cell count below 300 cells $/ \mathrm{mm}^{3}$ [15]. Nevertheless, one hospital based case series study done in Ethiopia showed that age was significantly associated with HIV-VL coinfection [16]. Therefore, there is a scarcity of data on factors associated with HIV-VL coinfected patients in Ethiopian context.

This study is aimed to determine the prevalence of HIV and associated factors among VL infected patients in the endemic areas of Northwest Ethiopia. The findings of this study could be useful evidence for scholars who are interested in the field and the ART programs undertaken by the government and non - government organizations.

\section{Methods}

Study design

Facility based cross-sectional study design was employed to assess the prevalence of HIV and associated factors among VL patients who visited the health facilities in Northwest Ethiopia.

\section{Study settings and population}

From the VL treatment centers found in the Northwest Ethiopia, three hospitals and one health center were selected purposely considering the availability of invasive VL diagnostic methods such as demonstration of parasite from spleen/lymph node aspiration or positive serology test if the patient has no VL history. In addition to VL diagnostic method, we also considered the availability of Fluorescence Activate Cell Sorting (FACS) count machine for CD4 count and $\mathrm{CBC}$ (complete blood count) machine. Hospitals and Health centers found in the study area that fulfilled the above considerations were considered as clusters (units). The selected Hospitals and Health center are the only health facilities that have well organized VL diagnosis and treatment centers found in the study area. The excluded health facilities in our study have not yet started diagnosing and treating VL patients. If VL patients visited these health facilities then they will be referred to one of the selected health facilities.

The study was carried out at four different sites in Northwest Ethiopia. The first site was Abdrafi inpatient kala-azar treatment center located in Abdrafi; at this health center medical services are provided for patients with Leishmaniasis, HIV-VL coinfection and snake bite. The second site was kala-azar treatment and research center in the University of Gondar Hospital located in Gondar; at this center both outpatient and inpatient medical services are provided for patients with Leishmaniasis and HIV-VL coinfection in addition to the comprehensive medical service from other units of the University of Gondar Hospital. The third site was Kahsay Aberra Hospital located in Humera kala-azar treatment center; at this center both outpatient and inpatient medical services are provided for patients with Leishmaniasis, HIV-VL coinfection and many other hospital level services. The fourth site was Metema Hospital located in Metema kala-azar treatment center; at this center both outpatient and inpatient medical services are provided for patients with Leishmaniasis, HIV-VL coinfection and many other hospital level services.

The sample size (n) was computed by single population proportion formula $n=\left[(\mathrm{z} \alpha / 2)^{2} \times \mathrm{P}(1-\mathrm{P})\right] / \mathrm{d}^{2}$ by assuming $95 \%$ confidence level of $Z_{\alpha / 2}=1.96$, margin of error $5 \%$ and we have taken proportion of $18.1 \% \mathrm{HIV}$ VL coinfection conducted in endemic area of Amahara region [10]. By considering this; the calculated sample 
size was 226.8 with adjustments for design effect of 2 and for non response rate $(10 \%)$ the final sample size became 500 . The included study participants were 155 , 79, 89 and 139 patients at Abdrafi health center, Metema hospital, Humera hospital and University of Gondar hospital respectively.

The study population was all VL patients who visited VL treatment facilities found in Northwest Ethiopia. Cluster sampling technique was employed to include study participants. Therefore, Abdrafi Health center, Metema Hospital, Humera Hospital, and University of Gondar Hospital were the four selected clusters. All VL diagnosed patients who visited and admitted to these facilities were included in the study. In addition to this, we have included HIV-VL coinfected patients who already started receiving ART and VL patients who are already started VL treatment during the beginning of the study. All the included study participants were admitted to the selected VL treatment centers and their admission was because of their VL infections and not for other disease. Participants who were mentally incompetent and unable to speak to undertook consent and interviews were excluded from the study. The study period was from October 7/2015 to August 5/2016.

\section{Measurements}

Diagnosis of VL was conducted according to the guidelines for the diagnosis of Leishmaniasis in Ethiopia [17]. The WHO case definition of VL was used as a starting point; history of fever for more than 2 weeks, malaria excluded, in combination with wasting and either splenomegaly or lymphadenophaty [18]. A patient whose illness met this case definition and who had no previous VL treatment was diagnosed serologically by positive rK39 rapid diagnostic test (Diamed-IT-Leish, DiaMed AG) [19]. Patients with previous VL history underwent splenic or lymph node aspiration and VL confirmed parasitologically. A severely ill patient with a negative rK39 test was aspirated without delay, so that a diagnosis could be made as quickly as possible.

The selected health facilities have got both parasitological and serological (rk39 dipstick test) VL diagnosis methods. The standard means of parasitological diagnosis in VL entails microscopy and/or culture from spleen, bone marrow or lymph node. While highly accurate, the procedure is invasive, painful, and carries the risk of potentially fatal bleeding. In order to avoid such problems and taking into account the patient have no previous $\mathrm{VL}$ infection we used serological tests for $46.32 \%$ of the included study participants. But if the patient has previous history of VL infection then the serological tests were less effective. Hence, we have used parasitological tests for $53.68 \%$ of the included study participants. VL diagnosis was made by laboratory technologists working in the selected health facilities. After spleen or bone marrow aspirations were made as appropriate, laboratory technologists and/or senior clinicians read the aspirates at least twice. Wright or Giemsa staining was used as available in the health facilities.

Provider-initiated testing and counseling for HIV was offered to all VL patients. The HIV diagnosis was based on the national algorithm with two serial positive rapid test results; The KHB (Shanghi Kehua Bio-engineering, ltd, 2008, China) HIV test was used to diagnose HIV. For positive results, confirmation were done using STATPAK test (chembio diagnostic system Inc, 2008, USA). In case of discrepancy between the two tests, Uni-Gold ${ }^{\mathrm{m}}$ (Trinity Biotech PLC, Bray, Ireland) was used as a tie breaker. As VL is considered a stage IV-defining illness in HIV patients [18, 20], all patients were given ART as soon as they were stabilized from their acute illnesses. ART regimens follow the national guidelines: tenofovir-lamivudineefavirenz; zidovudine-lamivudine-efavirenz; or zidovudinelamivudine-nevirapine [21] Second-line ART consists of protease inhibitor-based combination regimens.

The clinical and treatment related data's were extracted from the chart of each patient by using checklist. Data on demographic factors were collected by using structured and pretested questionnaire which was developed by the investigators. The structured questionnaire was prepared in English version and translated into Amharic (local language) and again back to English to confirm the correctness of the translation. The data collectors were 4 nurses and 4 laboratory technologist. We employed four physicians and health officers as the supervisors of the data collectors. One day training was given to the data collectors and supervisors on the data collection tool and sampling techniques. Supervision was held regularly during data collection period. The collected data was reviewed and checked for completeness and relevance in each day before going to the next day data collection.

\section{Definition of variables}

The dependent variable was HIV-VL coinfection and independent variables were socio-demographic variables, clinical characteristics and treatment related variables. The variables were defined as categorical variables with the following:

HIV-VL coinfection - A person who was positive for both VL and HIV diagnosis.

Spleen size - Spleen size of $15 \mathrm{~cm}$ and above is defined as a huge splenomegaly, and is associated with infarction, anemia and dragging abdominal pain.

Altitude adjusted hemoglobin: - the adjustment is subtracted from each individual's observed hemoglobin level to calculate adjusted hemoglobin. The altitude of 
Gondar from sea level which is found to be 2,133 m which will be adjusted by subtracting $0.8 \mathrm{~g} / \mathrm{dl}$ from the observed hemoglobin. The other places have an altitude of less than $1000 \mathrm{~m}$ and there is no adjustment. [22].

\section{Data analysis}

Each completed questionnaire for socio-demographic, clinical and treatment related variables was checked visually for completeness before fed to the computer. The data was entered into Excel, data cleanup and cross-checking was done and it was analyzed by using SPSS version 20. Descriptive statistics like frequencies and cross tabulation was performed. All variables with $P$-value $<0.2$ in bivariate analysis were included into a multivariate step wise backward logistic regression model. Goodness of fit for model was checked by Hosmer and Lemeshow test. Hence, the assumption fitted the test at $P$-value $=0.78>0.05$. Crude and adjusted odds ratios with $95 \%$ confidence interval was used to determine the strength of association between dependent and independent variables. Variables having $P$-value $\leq 0.05$ was considered as significant.

\section{Results}

A total of 462 study participants were included in the study with response rate of $92.4 \%$. The mean age $( \pm$ SD) of the included study participants was $26.47( \pm 9.19)$ years. Ninety six point five percent $(96.5 \%)$ of the study participants were males. Majority of the respondents 95.24\% were Orthodox Christians and $4.55 \%$ were Muslim in religion. Almost half of the study participants $(49.80 \%)$ were unable to read and write. Three hundred thirteen $(67.75 \%)$ were reported single. Two hundred twenty one $(47.84 \%)$ of the included study participants were farmers. Among the study participants 230 $(49.78 \%)$ were urban residents (Table 1$)$.

Eighty two (17.75 with 95\% CI; 14.30-21.40) of the included study participants were found to be HIV-VL coinfected patients. Among the HIV-VL coinfected patients $54(65.85 \%)$ were found to have a CD4 count less than 100 cells $/ \mathrm{mm}^{3}$. During diagnosis of VL the mean ( \pm SD) observed hemoglobin was $8.54 \mathrm{mg} / \mathrm{dl}( \pm 2.15)$ and $216(46.75 \%)$ of the study participants had hemoglobin less than $8.5 \mathrm{mg} / \mathrm{dl}$. After we adjusted for the altitude, the mean $( \pm$ SD) altitude adjusted hemoglobin was $8.29 \mathrm{mg} / \mathrm{dl}( \pm 2.14)$ and $226(48.92 \%)$ of the study participants had hemoglobin less than $8.29 \mathrm{mg} / \mathrm{dl}$. During diagnosis of VL 346 (74.89\%) of the study participants had a spleen size less than $15 \mathrm{~cm}$ (Table 1). Thirty two (39.02\%) of the coinfected patients were newly diagnosed for HIV-VL concurrent infection. Hence, they were not started antiretroviral treatment (Table 1).
In the bivariate analysis residence, marital status, employment and age of the participant were significantly associated with HIV-VL coinfection (Table 2).

The multivariate analysis was used to identify factors that were predictive of HIV-VL coinfection. Age, residence and employment were independently associated with HIV-VL coinfection (Table 3).

\section{Discussions}

This study focused on determining the prevalence of HIV and associated factors among VL infected patients. As a result, the prevalence was $17.75 \%$ and factors such as age, residence and employment were associated with HIV-VL coinfection. This is in line with other studies which reported socio-demographic factors might have an effect on HIV-VL coinfection [5, 10]. In addition to this, there are few emerging articles which recommend detailed studies on HIV-VL coinfection [23, 24].

As to this study result, the prevalence of HIV-VL coinfection was found to be $17.75 \%$. This finding is almost equal with the study conducted in Amhara region and Humera Northwest Ethiopia which showed that the proportion of HIV-VL coinfection was 18.1 and $18.6 \%$ respectively $[10,25]$. But this finding is lower than other studies done in Ethiopia by using similar method, Army Hospital, Addis Ababa from 1992 to 2001; Humera, Northwest Ethiopia from 1998 to 2000; Humera, Northwest Ethiopia, 2004; Gondar University Hospital, Northwest Ethiopia from 1999 to 2004; Gondar University and Humera Hospital, Northwest Ethiopia, from 2006 to 2008 in which HIV-VL coinfection was 48.5, 23, 28.5, 41 and $38.2 \%$ respectively [16, 26-29]. This might be due to the effectiveness of national strategy on interventions of behavioral change to reduce vulnerability to HIV infection designed by government and non government organizations. The other reason might be due to raised awareness on using interventions to prevent VL infection such as using insecticide treated bed net to prevent sandfly bites.

Age of the study participants was found to be significantly associated with HIV-VL coinfection. The study participants with age $\geq 30$ years had 22.58 times risk for HIV-VL coinfection than the participants with age $<30$ years. This was in line with the study done in Gondar University Hospital which showed that VL patients of age group $>20$ years were more than 3 times risk to have HIV infection as compared to those 20 years and below [16]. The age group distribution in coinfected patients is slightly higher in our study but the bottom line is HIV-VL coinfection mainly strikes adults. This study also gives additional evidence on the HIV-VL coinfection mainly risks the productive age groups (age $\geq 30$ ) and this will help to identify the target group for intervention. 
Table 1 Socio-demographic, clinical and treatment related characteristics of the study participants in Northwest Ethiopia, 2016

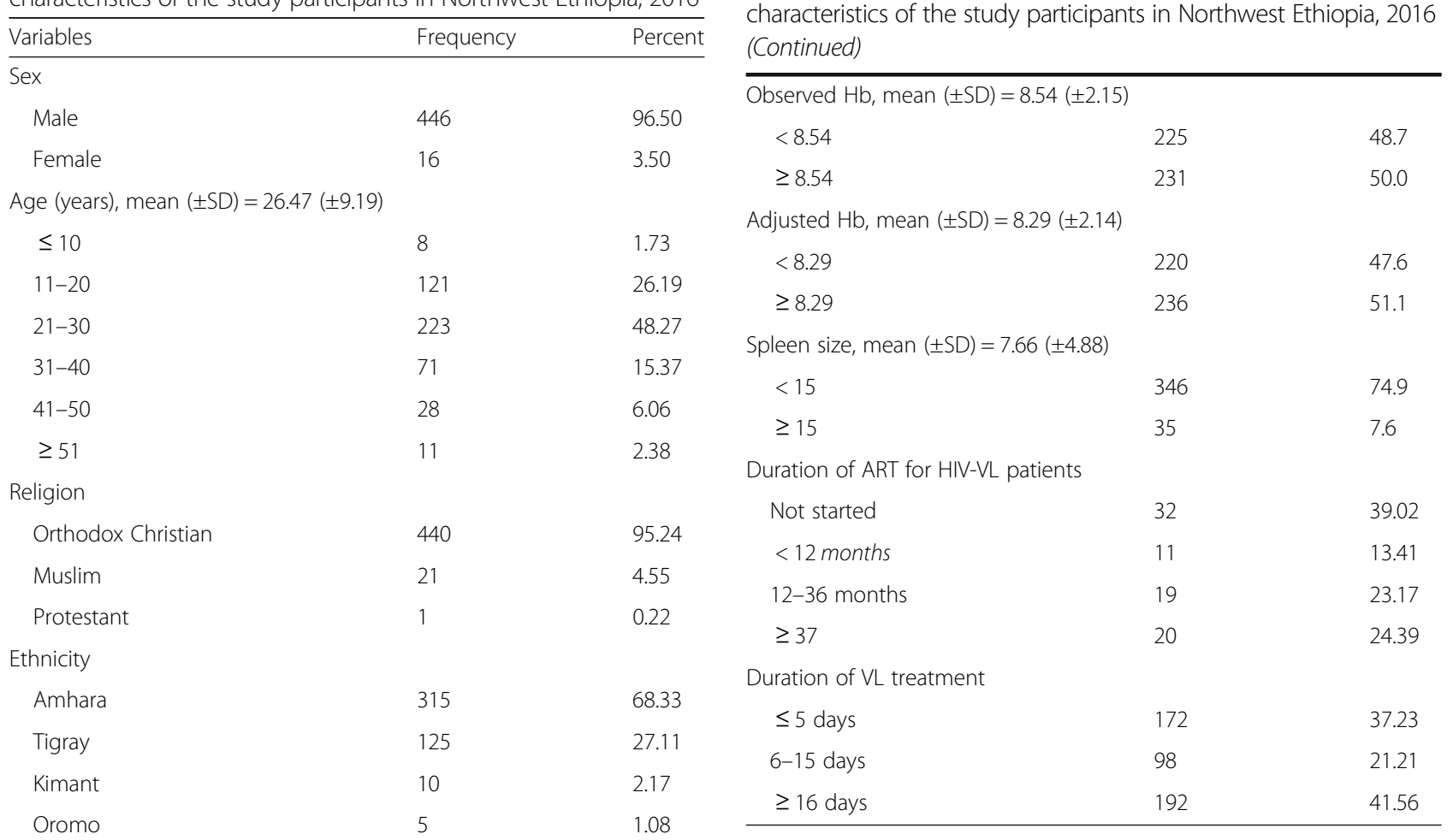

Others

Residence

Urban

Rural

Education level

Not read and write

Read and write

First cycle (1-8) \& above

Marital status

Single

Married

Divorced

Employment

Farmer

Daily laborer

Government employed

Non government employed

Merchant

Housewife

CD4+ count $(\mathrm{mg} / \mathrm{dl})$, mean (114.41)

$$
<100
$$
characteristics of the study participants in Northwest Ethiopia, 2016 (Continued)

Employment of the participants was positively associated with HIV-VL coinfection in which those who were daily laborers had 4.99 times risk for HIV-VL coinfection than farmers. In addition to this, other professionals such as government employees, non government employees, housewives and merchants together had 3.74 times risk for HIV-VL coinfection as compared to farmers. The possible explanation for the first one is daily laborers were mobile seasonal/migrant workers who came from highlands to VL endemic lowland areas for economical reason. Therefore, daily laborers are likely to have no pre-existing immunity to $\mathrm{VL}$ and/or lack of awareness about VL prevention methods as compared to farmers who were resided in the lowlands. The possible explanation of VL coinfection for the later is farmers were benefitted from the massive scale-up of insecticide treated nets for malaria control launched by Ministry of Health in 2005 that may therefore have collateral benefit for VL control [30]. The other reason might be due to effectiveness of health extension workers on interventions of behavioral change to reduce vulnerability of HIV and VL infection of farmers [31].

Residence of the study participants was found to be associated with HIV-VL coinfection. Those who were from urban residence had 2.2 times risk for HIV-VL coinfection as compared to rural residents. This finding is in line with the current national HIV/AIDS progress report of Ethiopia such as urban residents are more affected by HIV than rural residents [8].
Table 1 Socio-demographic, clinical and treatment related 
Table 2 Bivariate associations of the levels of HIV-VL coinfection with socio-demographic and clinical factors among VL infected patients in Northwest Ethiopia, 2016

\begin{tabular}{|c|c|c|c|c|}
\hline \multirow{2}{*}{$\begin{array}{l}\text { Characteristics of the } \\
\text { study participants }\end{array}$} & \multicolumn{2}{|c|}{ HIV-VL Coinfection } & \multirow[t]{2}{*}{ COR $(95 \% \mathrm{Cl})$} & \multirow[t]{2}{*}{$P$-value } \\
\hline & Yes & No & & \\
\hline Sex & & & & 0.579 \\
\hline Male & 80 & 366 & $1.53(0.34,6.87)$ & \\
\hline Female & 2 & 14 & $r$ & \\
\hline Age & & & & 0.001 \\
\hline$<30$ & 19 & 303 & $r$ & \\
\hline$\geq 30$ & 63 & 77 & $13.05(7.37,23.09)$ & \\
\hline Residence & & & & 0.001 \\
\hline Urban & 60 & 170 & $3.37(1.99,5.72)$ & \\
\hline Rural & 22 & 210 & $r$ & \\
\hline Marital status & & & & 0.001 \\
\hline Single & 35 & 278 & $r$ & \\
\hline Married & 20 & 77 & $2.06(1.13,3.78)$ & \\
\hline Divorced & 27 & 25 & $8.58(4.49,16.39)$ & \\
\hline Employment & & & & 0.010 \\
\hline Farmer & 28 & 193 & $r$ & \\
\hline Daily laborer & 35 & 103 & $2.34(1.35,4.07)$ & \\
\hline Others $^{a}$ & 19 & 84 & $1.56(0.83,3.95)$ & \\
\hline Education & & & & 0.124 \\
\hline Not read and write & 41 & 189 & $1.24(0.73,2.10)$ & \\
\hline Read and write & 14 & 37 & $2.16(1.03,4.52)$ & \\
\hline First cycle and above & 27 & 154 & $r$ & \\
\hline Observed $\mathrm{Hb}$ & & & & 0.385 \\
\hline$<8.54$ & 43 & 182 & $1.24(0.76,2.01)$ & \\
\hline$\geq 8.54$ & 37 & 194 & $r$ & \\
\hline Altitude adjusted $\mathrm{Hb}$ & & & & 0.554 \\
\hline$<8.29$ & 41 & 179 & $1.16(0.71,1.88)$ & \\
\hline$\geq 8.29$ & 39 & 197 & $r$ & \\
\hline Spleen size $(\mathrm{cm})$ & & & & 0.304 \\
\hline$<15$ & 64 & 282 & $r$ & \\
\hline$\geq 15$ & 4 & 31 & $0.57(0.19,1.67)$ & \\
\hline CD4+ count (mg/dl) & & & & 0.651 \\
\hline$<100$ & 54 & 260 & $r$ & \\
\hline$\geq 100$ & 28 & 120 & $1.12(0.66,1.92)$ & \\
\hline
\end{tabular}

$r$ reference, a government employed, non government employed, housewife and merchant, the stated $P$-values are the overall $P$-values. Pearson Chi-square test was used to generate the $P$-values

The reason behind the VL coinfection might be those urban residents had a travel history to endemic areas for different reasons such as to work as a daily laborer or for other reason like trading purpose. Therefore, they might have no pre-existing immunity to $\mathrm{VL}$ and/or lack of awareness of $\mathrm{VL}$ prevention mechanism as compared to farmers who permanently resided in low land areas.
Table 3 Multivariate association of the levels of HIV-VL coinfection with factors among VL infected patients in Northwest Ethiopia, 2016

\begin{tabular}{|c|c|c|c|c|c|}
\hline \multirow[t]{2}{*}{ Variables } & \multicolumn{2}{|c|}{$\begin{array}{l}\text { HIV-VL } \\
\text { coinfection }\end{array}$} & \multirow[t]{2}{*}{ COR $(95 \% \mathrm{Cl})$} & \multirow[t]{2}{*}{ AOR $(95 \% \mathrm{Cl})$} & \multirow[t]{2}{*}{$P$-value } \\
\hline & Yes & No & & & \\
\hline \multicolumn{6}{|l|}{ Age } \\
\hline$<30$ & 19 & 303 & $r$ & $r$ & $P=0.001$ \\
\hline$\geq 30$ & 63 & 77 & $13.05(7.37,23.09)$ & $22.58(11.34,45.01)$ & \\
\hline \multicolumn{6}{|l|}{ Residence } \\
\hline Urban & 60 & 170 & $3.37(1.99,5.72)$ & $2.20(1.16,4.17)$ & $P=0.016$ \\
\hline Rural & 22 & 210 & $r$ & $r$ & \\
\hline \multicolumn{6}{|l|}{ Marital status } \\
\hline Single & 35 & 278 & $r$ & & \\
\hline Married & 20 & 77 & $2.06(1.13,3.78)$ & & \\
\hline Divorced & 27 & 25 & $8.58(4.49,16.39)$ & & \\
\hline \multicolumn{6}{|l|}{ Employment } \\
\hline Farmer & 28 & 193 & $r$ & $r$ & $P=001$ \\
\hline Daily laborer & 35 & 103 & $2.34(1.35,4.07)$ & $4.99(2.33,10.68)$ & \\
\hline Others $^{a}$ & 19 & 84 & $1.56(0.83,3.95)$ & $3.74(1.57,8.93)$ & \\
\hline \multicolumn{6}{|c|}{ Educational status } \\
\hline $\begin{array}{l}\text { Not read } \\
\text { and write }\end{array}$ & 41 & 189 & $1.24(0.73,2.10)$ & & \\
\hline $\begin{array}{l}\text { Read and } \\
\text { write }\end{array}$ & 14 & 37 & $2.16(1.03,4.52)$ & & \\
\hline $\begin{array}{l}\text { First cycle } \\
\& \text { above }\end{array}$ & 27 & 154 & $r$ & & \\
\hline
\end{tabular}

In our study, CD4 cell count, $\mathrm{Hb}$, and spleen size of included patients did not significantly associated with HIV-VL coinfection but this may be because of the small sample size of the study and majority of the study participants were male (97\%). This is therefore makes unlikely to obtain a significant association of the HIV prevalence in this population since females are twice affected than male population with HIV in Ethiopia [8]. Indeed, one study has shown that CD4 cell count is important predictor of HIV-VL coinfection [15].

The findings of this study should be interpreted with some limitations. The study relies on participants who manage to come to the health institutions. We might not get HIV-VL coinfected patients who couldn't visit the health facilities for different reason. Therefore, the estimated prevalence may not exactly show the HIV-VL coinfection burden in the community. Moreover, self report of historical VL events of the study participants were used during VL diagnosis. Hence, recall bias could have present. Majority of the study participants were male sex and a little younger age groups; these may introduce some bias to our study. The reason for not including more female sex and older age groups were HIV-VL coinfected 
female and older age group patients were not found at all the health centers during the study period.

\section{Conclusion}

HIV-VL coinfection in the Northwest Ethiopia was found to be low. Age, residence and employment were independently associated with HIV-VL coinfection in the Northwest Ethiopia. It is better to design interventions to prevent and control HIV-VL coinfection for productive age groups (age $\geq 30$ ) and daily laborers.

\section{Abbreviations}

ART: Antiretroviral therapy; ARV: Antiretroviral drug; CBC: Complete blood count; CD4: Cluster of differentiation 4; FACS: Fluorescence Activate Cell Sorting; rK39: Recombinant K 39; SPSS: Statistical package for social science; VL: Visceral Leishmaniasis; WHO: World Health Organization

\section{Acknowledgment}

We forward our appreciation to the treatment center managers of all treatment sites for allowing us to conduct this research. Our special appreciation will goes to the study participants for their volunteer participation. Finally we thank our colleagues especially Dr. R.P. Raju in the Institute of Public Health for their support throughout the process.

\section{Funding}

The study was supported by University of Gondar.

\section{Availability of data and materials}

The datasets supporting the conclusions of this article are available upon request to the corresponding author. Due to data protection restrictions and participant confidentiality, we do not make participants data publicly available.

\section{Authors' contributions}

MA, MW, NM and AG participated in the conception and design of the study, MA collected data, MA, MW, NM and AG interpreted the data. MA drafted the initial manuscript. All authors read and approved the final manuscript, contributed the critical review and the content.

\section{Competing interest}

The authors declare that they have no competing interests.

\section{Consent for publication}

Not applicable.

\section{Ethics approval and consent to participate}

Ethical clearance was obtained from Institutional Review Board of University of Gondar (2015/996). Then official letter obtained from administrative body of Gondar university hospital, Humera Hospital, Metema Hospital and Abdrafi Health Center. The purpose of study was well explained to the study participants and informed consents were obtained. Confidentiality was maintained at all levels of the study by avoiding use of name and other identifiers. Participants' involvement in the study was on voluntary basis; participants who were unwilling to participate in the study and those who wish to quit their participation were informed to do so without any restriction.

\section{Author details}

'Institute of Public Health, College of Medicine and Health Sciences, University of Gondar, Gondar, Ethiopia. ${ }^{2}$ Department of Public Health, St. Paul's Hospital Millennium Medical College, Addis Ababa, Ethiopia. ${ }^{3}$ School of Medicine, College of Medicine and Health Sciences, University of Gondar, Gondar, Ethiopia.
Received: 20 August 2016 Accepted: 10 February 2017

Published online: 17 February 2017

\section{References}

1. Desjeux $P$. The increase in risk factors for leishmaniasis worldwide. Trans $R$ Soc Trop Med Hyg. 2001;95:239-43.

2. WHO: Visceral Leishmaniasis. http://www.who.int/leishmaniasis/visceral leishmaniasis/en/2016

3. Wolday D, Akuffo H, Demissie A, Britton S. Role of Leishmania donovani and its lipophosphoglycan in CD4+ T-cell activation-induced human immunodeficiency virus replication. Infect Immun. 1999;67:5258-64.

4. Cruz I, Nieto J, Moreno J, Canavate C, Desjeux P, Alvar J. Leishmania/HIV co-infections in the second decade. Indian J Med Res. 2006;123:357-88.

5. Desjeux P, Alvar J. Leishmania/HIV co-infections: epidemiology in Europe. Ann Trop Med Parasitol. 2003:97 Suppl 1:3-15.

6. Alvar J, Aparicio P, Assefa A, Den Boer M, Canavate C, Dedet JP, et al. The Relationship between Leishmaniasis and AIDS: the second 10 years. Clin Microb Rev. 2008:21(2):334-59.

7. Horst TR, Colline SM, Ritemeijer K, Bogale A, Davidson NR. Concordant HIV infection and Visceral Leishmaniasis in Ethiopia: The influence of Antiretroviral Treatment and other factors on outcome. Clin Infect Dis. 2008;46:1702-9.

8. WHO: HIV/AIDS progress in 2014. wwwafrowhoint/en/ethiopia/whocountry-office-ethiopiahtml 2015.

9. Ermias D, Lutgarde L, Koert R, Marleen B, Asrat H, Van G. Visceral Leishmaniasis and HIV Coinfection in East Africa. PLoS Negl Trop Dis. 2014;8:6.

10. Mulat $Y$, Bayeh A, Wondemagegn M, Yohannes Z, Belay B. Proportional of Visceral Leishmaniasis and Human immune deficiency virus co-infection among clinically confirmed visceral leishmaniasis patients at the endemic foci of the Amahara National Regional State, North-West Ethiopia. Am J Biol Life Sci. 2014:2(1):1-7.

11. Gradoni L, Scalone A, Gramiccia M, Troiani M. Epidemiological surveillance of leishmaniasis in HIV-1-infected individuals in Italy. AIDS. 1996:10:785-91.

12. Medrano F, Herna'ndez-Quero J, Jime'nez E, Pineda J, Rivero A, Sa'nchezQuijano A, et al. Visceral leishmaniasis in HIV-1-infected individuals: a common opportunistic infection in Spain? AIDS. 1992;6:1499-503.

13. Amela C, Lo'pez-Gay D, Alberdi J, Castilla J. Injecting drug use as risk factor for visceral leishmaniasis in AIDS patients. Eur J Epidemiol. 1996;12:91-2.

14. PINEDA JA GALLARDOJA, AS JM, DELGADO J, REGORDA'N C, MORILLAS F, et al. Prevalence of and Factors Associated with Visceral Leishmaniasis in Human Immunodeficiency Virus Type 1-Infected Patients in Southern Spain. J Clini Microbiol. 1998;36:9.

15. Rosa R, Pineda JA, Delgado J, Macías J, Morillas F, Mira JA, et al. Incidence of and Risk Factors for Symptomatic Visceral Leishmaniasis among Human Immunodeficiency Virus Type 1-Infected Patients from Spain in the Era of Highly Active Antiretroviral Therapy. J Clini Microbiol. 2002;40:3.

16. Mengistu G, Ayele B. Visceral leishmaniasis and HIV co-infection in patients admitted to Gondar University Hospital, North West Ethiopia. Ethiop J Health Dev. 2007;21:53-60

17. FMOH: quideline for diagnosis, treatment and prevention of Leishmaniasis in Ethiopia. 2013. http://www.moh.gov.et/

18. WHO. Manual on visceral leishmaniasis. Geneva: Report WHO/Leish/9640; 1996

19. Meredith S, Kroon NC, Sondorp E, et al. Leish-KIT, a stable direct agglutination test based on freeze-dried antigen for serodiagnosis of visceral leishmaniasis. J Clin Microbiol. 1995;33:1742-5.

20. WHO. Technical, report: Control of the leishmaniasis. Geneva: Report of a meeting of the WHO expert committee; 2010.

21. $\mathrm{FMOH}$. Guidelines for management of opportunistic infections and antiretroviral treatment in adolescents and adults in Ethiopia. Addis Ababa: Federal HIV/AIDS prevention and control office and Federal Minsitry of Health; 2007.

22. Sullivan M, Zuguo M, Grummer-Strawn L, Ibrahim P. Haemoglobin adjustments to define anaemia. Trop Med Int Health. 2008;13(8):1267-71.

23. Guerin PJ, Piero O, Shyam S, Marleen B, Croft SL, Philippe D, et al. Visceral leishmaniasis: current status of control, diagnosis, and treatment, and a proposed research and development agenda. Lancet Infect Dis. 2002:2:494-501.

24. Lindoso J, Cota GF, Da Cruz AM, Goto H, Maia-Elkhoury ANS, et al. Visceral Leishmaniasis and HIV Coinfection in Latin America. PLoS Negl Trop Dis. 2014;8(9), e3136. doi:10.1371/journal.pntd.0003136. 
25. Ritmeijer K, Veeken H, Melaku Y, Leal G, Amsalu R, et al. Ethiopian visceral leishmaniasis: generic and proprietary sodium stibogluconate are equivalent; HIV co-infected patients have a poor outcome. Trans R Soc Trop Med Hyg. 2001:95:668-72.

26. Hailu A, Gebre-Michael T, Berhe N, Balkew M. Leishmaniasis in Ethiopia: The Ecology and Epidemiology of Health and Disease in Ethiopia. Addis Ababa: Shama Books; 2006. p. 615-34.

27. Hurissa Z, Gebre-Silassie S, Hailu W, Tefera T, Lalloo DG, et al.: Clinical characteristics and treatment outcome of patients with visceral leishmaniasis and HIV co-infection in northwest Ethiopia. Trop Med Int Health. 2010;15:848-55. doi:10.1111/j1365-3156201002550x.

28. Lyons S, Veeken H, Long J. Visceral leishmaniasis and HIV in Tigray, Ethiopia. Trop Med Int Health. 2003;8:733-9.

29. Ritmeijer K, Dejenie A, Assefa Y, Hundie TB, Mesure J, et al.: A comparison of miltefosine and sodium stibogluconate for treatment of visceral leishmaniasis in an Ethiopian population with high prevalence of HIV infection. Clin Infect Dis. 2006:43:357-64. doi:10.1086/505217.

30. FMOH: Ethiopia National Malaria Indicator Survey 2011: Technical Summary. Addis Ababa, Ethiopia pp 1-11 2011. http://www.moh.gov.et/.

31. FMOH: Health extension program in Ethiopia. Addis Ababa, Ethiopia. 2007 http://www.moh.gov.et/.

\section{Submit your next manuscript to BioMed Central} and we will help you at every step:

- We accept pre-submission inquiries

- Our selector tool helps you to find the most relevant journal

- We provide round the clock customer support

- Convenient online submission

- Thorough peer review

- Inclusion in PubMed and all major indexing services

- Maximum visibility for your research

Submit your manuscript at www.biomedcentral.com/submit 